\title{
DESEN VOLVIMENTO E ACEITAÇÃO SENSORIAL DE COOKIES DE COCO ADICIONADOS DE CONCENTRADO PROTEICO DE PESCADO
}

\author{
MARINA CABRAL REBOUÇAS* \\ MARIA DO CARMO PASSOS RODRIGUES** \\ MARIA FLÁVIA AZEVEDO DA PENHA ${ }^{\star * *}$ \\ VANDERSON DA SILVA COSTA****
}

\begin{abstract}
O objetivo deste trabalho foi desenvolver formulações de biscoitos do tipo cookie, sabor coco, com e sem adição de concentrado proteico de pescado, comparando-as em relação à aceitabilidade sensorial, atitude de compra e idealidade da crocância. Foram desenvolvidas três formulações de cookies, uma padrão e as outras com adição de $51 \%$ e $83 \%$ de concentrado proteico de pescado. A aceitação sensorial dos cookies foi verificada mediante escala hedônica, avaliando-se os atributos aparência, aroma, sabor e textura, bem como a aceitação global. Avaliou-se a intenção de compra dos consumidores em relação ao produto por meio de escala de atitude de compra e o grau de idealidade da crocância com o auxílio da escala do ideal. Os cookies padrão e adicionados de $51 \%$ de concentrado proteico de pescado obtiveram aceitação, não diferindo significativamente em nenhum atributo sensorial analisado. O cookie adicionado de $83 \%$ de concentrado proteico não obteve aceitação satisfatória, tornando inviável a sua comercialização devido ao fato de modificar negativamente as características sensoriais do produto.
\end{abstract} PALAVRAS-CHAVE: COOKIES; CONCENTRADO PROTEICO DE PESCADO; RESÍDUOS -
APROVEITAMENTO; ANÁLISE SENSORIAL.

* Doutoranda em Ciência e Tecnologia de Alimentos, Departamento de Tecnologia de Alimentos, Universidade Federal do Ceará (UFC), Fortaleza, CE (e-mail: marina_reboucas@hotmail.com).

** Professora, Departamento de Tecnologia de Alimentos, UFC, Fortaleza, CE (e-mail: carminha@ufc.br).

*** Mestranda em Ciência e Tecnologia de Alimentos, Departamento de Tecnologia de Alimentos, UFC, Fortaleza, CE (e-mail: mflaviaaz@gmail.com).

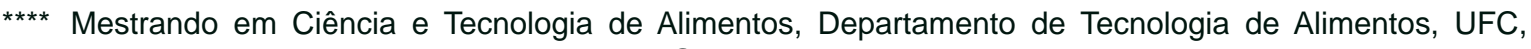
Fortaleza, CE (e-mail: vandersonsilvacosta@yahoo.com.br). 


\section{INTRODUÇÃO}

A legislação brasileira, por meio da RDC $n^{\circ} 263$ de 22 de setembro de 2005, define biscoito como sendo o produto obtido pela mistura da farinha(s), amido(s) e/ou fécula(s) com outros ingredientes, os quais são submetidos ao processo de amassamento e cocção, fermentados ou não, podendo apresentar coberturas, recheios, formato e textura diversos (BRASIL, 2005).

Os biscoitos do tipo cookie apresentam diversas vantagens para a sua comercialização devido ao grande consumo, principalmente entre crianças, sua vida-de-prateleira relativamente longa e boa aceitação (FASOLIN et al., 2007; TSEN, 1976). Diversas pesquisas vêm sendo desenvolvidas visando a fortificação de biscoitos com fontes de proteínas ou fibras, devido ao forte apelo nutricional desses produtos (FASOLIN et al., 2007).

A falta de reconhecimento dos resíduos das indústrias de beneficiamento de pescado como matéria-prima e fonte para utilização no desenvolvimento de outros produtos gera o desperdício de grandes quantidades de subprodutos (PESSATI, 2001; STEVANATO et al., 2007). Em alguns casos, a produção de resíduos chega a alcançar cerca de $70 \%$ do peso inicial da matéria-prima na aquicultura, pesca e durante o processamento do pescado (SEIBEL e SOUZASOARES, 2003).

O concentrado proteico de pescado (CPP), subproduto da indústria pesqueira, pode ser obtido de espécies não comerciais, como também de resíduos da industrialização do pescado. A utilização da carne mecanicamente separada de pescado para obtenção de CPP só foi possível graças ao aparecimento de equipamentos capazes de recuperar o material agregado às espinhas (PESSATI, 2001).

Os produtos à base de pescado são alimentos com alto valor nutritivo, apresentando proteínas com digestibilidade ao redor de $90 \%$, além de serem fontes de cálcio, ácidos graxos insaturados e vitaminas do complexo B (KIRSCHNIK, 2007).

A análise sensorial, efetuada mediante a utilização dos sentidos humanos, tem como finalidade verificar a aceitação de produtos alimentícios. Dessa forma, as sensações que resultam da interação dos órgãos humanos com os alimentos são usadas para avaliar sua qualidade, aceitabilidade por parte do consumidor e em pesquisas para o desenvolvimento de novos produtos (STONE e SIDEL, 2004).

Os testes sensoriais afetivos objetivam conhecer a opinião de determinado grupo de consumidores (público alvo) com relação ao produto de interesse (CHAVES e SPROSSER, 2001). Por meio dos métodos sensoriais afetivos consegue-se medir quanto o consumidor gostou ou desgostou de determinado produto, bem como avaliar a sua preferência (STONE e SIDEL, 2004).

A utilização do concentrado proteico de pescado para fortificação de biscoitos do tipo cookie apresenta-se como excelente forma de aproveitamento de resíduos industriais, além de contribuir para o enriquecimento nutricional desse produto. Nesse contexto, objetivou-se desenvolver formulações de biscoitos do tipo cookie sabor coco, com e sem adição de concentrado proteico de pescado, comparando-as em relação à aceitabilidade sensorial, atitude de compra e idealidade da crocância.

\section{MATERIAL E MÉTODOS}

\subsection{OBTENÇÃO DA CMS DE TILÁPIA DO NILO}

Para a obtenção da carne mecanicamente separada (CMS) foram utilizados resíduos da filetagem da tilápia do Nilo (Oreochromis niloticus), cedidos pelo Centro de Pesquisas Ictiológicas 
Rodolpho Von Ihering (Pentecoste, CE) do Departamento Nacional de Obras Contra as Secas (DNOCS). Os resíduos utilizados foram: carcaças, nadadeiras peitorais e aparas do toalete do filé.

Para recuperação da carne utilizou-se máquina despolpadora de pescado, marca High Tech, modelo HT 250. A polpa do pescado foi embalada em sacos plásticos de polietileno com capacidade para 2 quilos e armazenadas à temperatura de aproximadamente $-18^{\circ} \mathrm{C}$.

\subsection{PROCESSO DE OBTENÇÃO DO CONCENTRADO PROTEICO DE PESCADO}

O concentrado proteico foi obtido a partir da CMS de tilápia do Nilo, conforme modificação do método desenvolvido por Vidal (2007).

A CMS descongelada foi imersa em água potável refrigerada e submetida à agitação durante 15 minutos, seguida de filtração para eliminação do excesso de água. Logo após, realizouse a desodorização com solução de ácido fosfórico 0,002\% e agitação durante 15 minutos, sendo o excesso da solução eliminado por filtração e prensagem. O resíduo foi seco em estufa com circulação forçada de ar à temperatura de $72^{\circ} \mathrm{C}$ durante 16 horas. Após seco, o produto foi triturado até a obtenção de pó de granulometria uniforme. A etapa de deslipidificação foi realizada posteriormente, colocando-se o material seco em contato com etanol na proporção de 2:1 (etanol:CPP). O material foi novamente seco em estufa com circulação forçada de ar à temperatura de $60^{\circ} \mathrm{C}$ por 2 horas. Finalmente, o CPP foi acondicionado em embalagem de polietileno biorientado metalizado e selado a vácuo.

A modificação realizada na metodologia de obtenção de CPP a partir da tilápia do Nilo desenvolvida por Vidal (2007) consistiu no aumento da concentração da solução de ácido fosfórico em $0,001 \%$ e na inversão da ordem da deslipidificação, originalmente efetuada depois da etapa de desodorização e não após a secagem.

\subsection{CARACTERIZAÇÃO QUÍMICA DO CONCENTRADO PROTEICO DE PESCADO}

Caracterizou-se o CPP obtido mediante análises de umidade, lipídios, proteínas e cinzas, efetuadas de acordo com metodologias da AOAC (1995).

\subsection{ELABORAÇÃO DOS BISCOITOS}

Foram desenvolvidos três tipos de biscoitos do tipo cookies: um padrão sem adição de CPP (Cookie P), outro adicionado de aproximadamente 51\% de CPP (Cookie 51\% CPP) e o terceiro com aproximadamente 83\% de CPP (Cookie 83\% CPP).

Para a elaboração dos cookies utilizaram-se os seguintes ingredientes: farinha de trigo, gordura vegetal hidrogenada, açúcar, água mineral, coco desidratado, leite em pó desnatado, fermento químico em pó e aroma de coco. Na elaboração dos cookies contendo $51 \%$ e $83 \%$ de CPP houve a substituição na concentração de farinha de trigo pelo percentual de concentrado adicionado (Tabela 1).

Para obtenção dos cookies foram misturados em batedeira convencional, em baixa rotação, a gordura vegetal hidrogenada, o açúcar e o aroma. Os demais ingredientes foram sendo adicionados separadamente até a obtenção de massa homogênea e coesa. Em seguida, a massa foi moldada para formação dos biscoitos em tamanhos padronizados, e colocados para cocção em forno doméstico na temperatura de $180^{\circ} \mathrm{C}$. 
TABELA 1 - PERCENTUAIS DAS MATÉRIAS-PRIMAS UTILIZADAS NAS FORMULAÇÕES DOS COOKIES DE COCO

\begin{tabular}{l|c|c|c|c|c|c}
\hline \multirow{2}{*}{ INGREDIENTES } & \multicolumn{2}{|c|}{ COOKIE P } & \multicolumn{2}{c|}{ COOKIE 51\% } & \multicolumn{2}{c}{ COOKIE 83\% } \\
\cline { 2 - 7 } & $(\mathrm{g})$ & $(\%)$ & $(\mathrm{g})$ & $(\%)$ & $(\mathrm{g})$ & $(\%)$ \\
\hline Farinha de trigo & 440 & 100 & 290 & 100 & 240 & 100 \\
$\begin{array}{l}\text { Gordura vegetal } \\
\text { hidrogenada }\end{array}$ & 190 & 43,18 & 190 & 65,51 & 190 & 79,16 \\
CPP & - & - & 150 & 51,72 & 200 & 83,33 \\
$\begin{array}{l}\text { Açúcar } \\
\text { Água mineral }\end{array}$ & 120 & 27,27 & 120 & 41,37 & 120 & 50 \\
$\begin{array}{l}\text { Coco ralado } \\
\text { desidratado }\end{array}$ & 105 & 23,86 & 105 & 36,20 & 105 & 43,75 \\
Leite em pó & 100 & 22,72 & 100 & 34,48 & 100 & 41,66 \\
desnatado & 30 & 6,81 & 30 & 10,34 & 30 & 12,50 \\
$\begin{array}{l}\text { Fermento químico } \\
\text { Aroma de coco }\end{array}$ & 10 & 2,27 & 10 & 3,44 & 10 & 4,16 \\
\hline
\end{tabular}

\subsection{AVALIAÇÃO SENSORIAL}

Avaliou-se a aceitação sensorial dos cookies desenvolvidos em Escala Hedônica estruturada mista de 9 pontos ( 9 = gostei muitíssimo, 5 = não gostei; nem desgostei; 1 = desgostei muitíssimo), mediante os atributos: aparência, aroma, sabor e textura, bem como a aceitação global (STONE e SIDEL, 1993).

A intenção de compra do produto baseou-se na impressão geral dos consumidores, sendo avaliada mediante Escala de Atitude de Compra estruturada mista de 5 pontos ( 5 = certamente compraria; 3 = tenho dúvidas se compraria; 1 = certamente não compraria) (MEILGAARD, CIVILLE e CARR, 1991).

Para avaliar a idealidade da crocância dos cookies utilizou-se o teste de Escala do Ideal estruturada mista de 9 pontos $(+4=$ extremamente mais crocante que 0 ideal, $0=$ ideal, $-4=$ extremamente menos crocante que o ideal) (MEILGAARD, CIVILLE e CARR, 1991).

Os testes sensoriais foram realizados no Laboratório de Análise Sensorial da Universidade Federal do Ceará, em cabines individuais com incidência de luz branca, sob condições controladas. Participaram da avaliação sensorial 42 consumidores de ambos os sexos e diferentes faixas etárias. As amostras foram servidas em copos plásticos descartáveis de $50 \mathrm{~mL}$ codificados com três dígitos aleatórios, de forma monádica sequencial, seguindo-se delineamento de blocos completos balanceados com relação à ordem de apresentação.

Os resultados do teste de Escala Hedônica foram analisados pela ANOVA e Teste de Tukey ao nível de significância de 5\% para verificar diferença entre as médias (MEILGAARD, CIVILLE e CARR, 1991). Os testes de Atitude de Compra e Escala do Ideal foram analisados mediante gráficos em histogramas de frequência (MINIM, 2006).

\section{RESULTADOS E DISCUSSÃO}

Com relação à caracterização química do CPP (Tabela 2) verificou-se teor de proteínas bastante elevado $(85,16 \%)$, o que indica seu grande potencial para enriquecimento de alimentos. A adição de $51 \%$ e $83 \%$ desse concentrado aos cookies proporcionará, em média, 43 g e 70 g de 
proteínas para cada $100 \mathrm{~g}$ de produto, respectivamente. Vale ressaltar que as proteínas de origem animal apresentam alto valor biológico.

O teor lipídico do CPP ficou em torno de 8,20\%, o que contribuirá com cerca de 4,18 g e $6,8 \mathrm{~g}$ de lipídios para cada $100 \mathrm{~g}$ de cookies adicionados de $51 \%$ e $83 \%$ de concentrado proteico, respectivamente. Apesar de elevado, o teor de lipídios deve-se em grande parte a ácidos graxos poliinsaturados, que são benéficos à saúde.

\section{TABELA 2 - RESULTADOS DAS ANÁLISES QUÍMICAS REALIZADAS NO CONCENTRADO PROTEICO DE PESCADO (Média \pm Desvio padrão)}

\begin{tabular}{cc}
\hline ANÁLISES QUÍMICAS & CPP \\
\hline Umidade (\%) & $4,85 \pm 0,021$ \\
Proteína (\%) & $85,16 \pm 0,481$ \\
Lipídios (\%) & $8,20 \pm 0,015$ \\
Cinzas (\%) & $2,45 \pm 0,003$ \\
\hline
\end{tabular}

Conforme os resultados do teste de Escala Hedônica (Tabela 3) não houve diferença significativa $(p>0,05)$ entre a amostra de cookie padrão e a adicionada de $51 \%$ de CPP em relação à todos os atributos sensoriais analisados. Os escores médios de aceitação obtidos por essas amostras em relação a todas as características sensoriais avaliadas foram maiores que 6,0 ("gostei ligeiramente" e "gostei moderadamente"), demonstrando boa aceitação dos cookies. Considerando o propósito de enriquecimento proteico dos cookies, a adição de 51\% de CPP à formulação mostrouse viável por não provocar alteração negativa das suas características sensoriais.

\section{TABELA 3 - RESULTADOS DA ACEITAÇÃO DAS AMOSTRAS DE COOKIES SABOR COCO COM RELAÇÃO AOS ATRIBUTOS SENSORIAIS (Média \pm Desvio Padrão)}

\begin{tabular}{lccccc}
\hline & Aparência & Aroma & Sabor & Textura & Impressão Global \\
\hline COOKIE P & $6,12 \pm 2,10^{\mathrm{a}}$ & $6,47 \pm 1,97^{\mathrm{a}}$ & $5,90 \pm 2,04^{\mathrm{ab}}$ & $6,53 \pm 1,91^{\mathrm{a}}$ & $6,14 \pm 1,75^{\mathrm{ab}}$ \\
COOKIE 51\% & $6,59 \pm 1,86^{\mathrm{a}}$ & $6,98 \pm 1,59^{\mathrm{a}}$ & $6,78 \pm 1,61^{\mathrm{a}}$ & $6,61 \pm 1,76^{\mathrm{a}}$ & $6,69 \pm 1,47^{\mathrm{a}}$ \\
COOKIE 83\% & $5,69 \pm 2,33^{\mathrm{a}}$ & $6,14 \pm 2,24^{\mathrm{a}}$ & $5,69 \pm 2,39^{\mathrm{b}}$ & $5,55 \pm 2,16^{\mathrm{b}}$ & $5,59 \pm 2,19^{\mathrm{b}}$ \\
\hline
\end{tabular}

ab Médias com letras iguais não diferem significativamente pelo Teste de Tukey ao nível de 5\% de probabilidade.

Deve-se ressaltar em relação à aparência e ao aroma que nenhuma das amostras diferiu significativamente, indicando aceitação equivalente em relação a essas características. Os escores médios de aceitação entre, aproximadamente, 6,0 e 7,0 ("gostei ligeiramente" e "gostei muito") indicam a aceitação desse biscoito com relação a esses atributos. A aceitação obtida para o aroma dos cookies adicionados de CPP demonstrou que o coco e o aroma utilizados nas formulações conseguiram se sobrepor ao odor e sabor do concentrado proteico.

O cookie adicionado de 83\% de CPP obteve médias de, aproximadamente, 5,0 com relação a todos os atributos sensoriais avaliados ("não gostei, nem desgostei" e "gostei ligeiramente"). A adição dessa concentração de CPP à formulação não é viável, pois altera negativamente as características sensoriais do produto, provocando a sua rejeição. Há que se avaliar a aceitabilidade de cookie com 
concentração intermediária de CPP para determinar se 51\% seria o limite de adição.

Com relação ao teste de atitude de compra (Figura 1), considerando-se o percentual de julgadores (63\%) com atitude positiva (valor 5 e 4 ), o cookie adicionado de $51 \%$ de CPP obteve melhor resultado, seguido pelo cookie padrão (49\%). O cookie adicionado de $83 \%$ de CPP obteve atitude de compra negativa de $41 \%$ dos julgadores (valor 1 e 2), seguido por $33 \%$ de indecisos (valor 3 ).

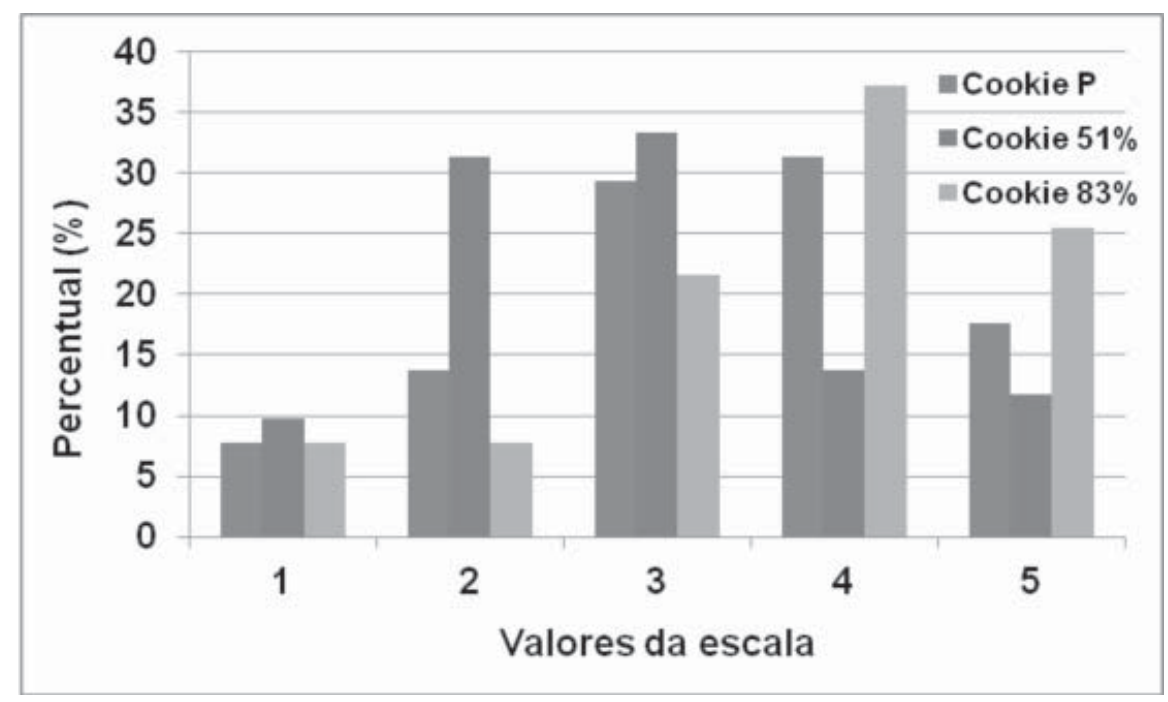

\section{FIGURA 1 - RESULTADOS DO TESTE DE ATITUDE DE COMPRA DOS COOKIES ELABORADOS}

Conforme os resultados do teste de Escala do Ideal (Figura 2), nenhuma das amostras atingiu o percentual mínimo de 70\% (MINIM, 2006) para serem consideradas ideais com relação a crocância. Esses resultados evidenciaram que as formulações deveriam passar por otimização com relação à essa característica sensorial. No entanto, elevado percentual de julgadores (50,98\%) avaliou a crocância dos Cookies P e com 51\% de CPP como sendo "ideal". Por não ocorrer maior concentração de julgadores em região específica da escala de intensidade, não é aconselhável modificar a formulação desses cookies tendo em vista o risco de diminuição da aceitação desse atributo pelos julgadores que o consideraram "ideal".

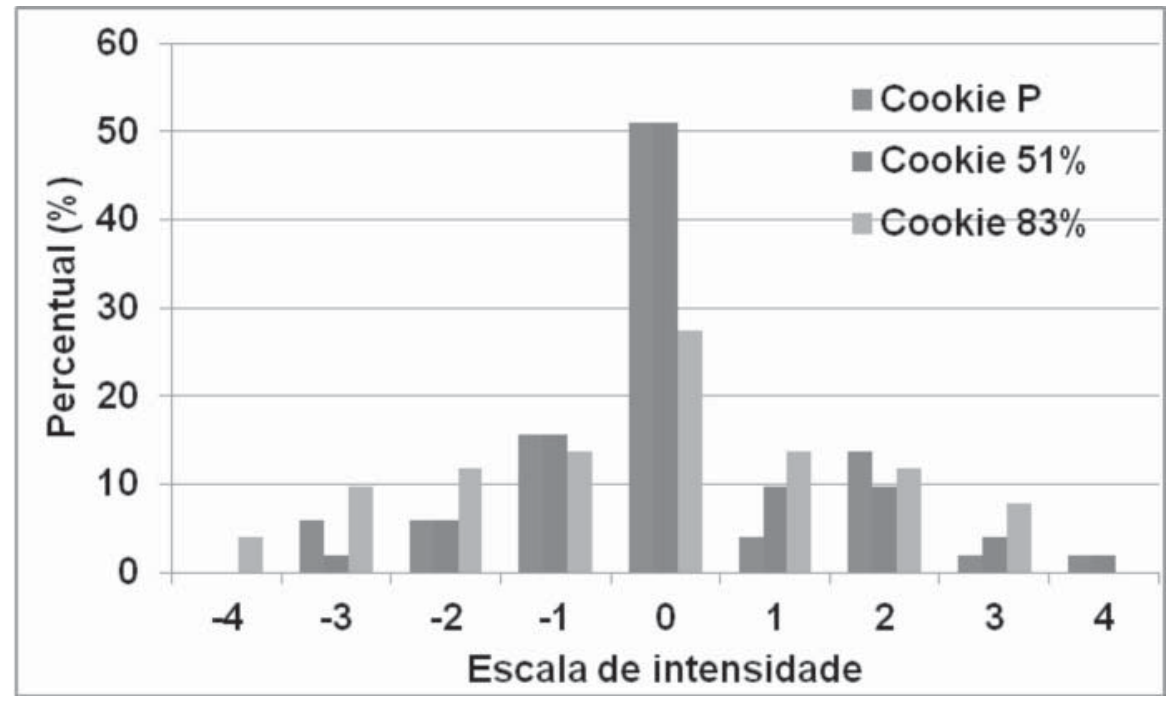

FIGURA 2 - RESULTADOS DO TESTE DE ESCALA DO IDEAL PARA A INTENSIDADE DA CROCÂNCIA DOS COOKIES DESENVOLVIDOS 
Apesar da distribuição bimodal obtida pelo cookie adicionado de $83 \%$ de CPP, maior percentual de julgadores $(39,20 \%)$ enquadrou-se na região de menor intensidade da escala (dos valores -1 ao -4), indicando que a sua crocância estava menos intensa que o ideal. O baixo percentual verificado no valor da escala correspondente ao "ideal" indica que essa amostra deve passar por otimização com relação à essa característica sensorial a fim de intensificá-la.

\section{CONCLUSÃO}

O cookie adicionado de $51 \%$ de concentrado proteico de pescado demonstrou viabilidade de comercialização, considerando sua aceitação em relação à formulação padrão em todos os atributos sensoriais analisados, além de alcançar maior atitude de compra. O cookie adicionado de 83\% de concentrado proteico não obteve aceitação satisfatória, tendo a sua crocância sido descrita como menos intensa que o ideal.

\section{ABSTRACT \\ DEVELOPMENT AND SENSORY ACCEPTANCE OF COCONUT COOKIES WITH ADDITION OF FISH PROTEIN CONCENTRATE}

The objective of this work was to develop formulations of coconut cookie, with and without addition of fish protein concentrate, comparing them about acceptability, purchase intent and degree of ideality of crispness. Were developed three formulations of cookies, a standard one and the other two with addition of $51 \%$ and $83 \%$ of fish protein concentrate. The sensory acceptance of cookies was evaluated using hedonic scale assessing sensory attributes of appearance, aroma, flavor, texture and global acceptance. The purchase intent was evaluated by the purchase attitude scale and the degree of ideal crispness was analyzed with the aid of the just right scale. The standard cookies and those added in $51 \%$ with fish protein concentrate presented good acceptance and did not differ significantly in any sensory attribute. The cookie with the addition of $83 \%$ of protein concentrate did not obtain satisfactory acceptance, which indicate that this concentration made it impossible their marketing due to the fact negative alteration on the sensory characteristics.

KEY-WORDS: COOKIES; FISH PROTEIN CONCENTRATE; BYPRODUCTS; SENSORY ANALYSIS.

\section{REFERÊNCIAS}

1 AOAC. Association of Official Analytical Chemists. Official methods of analysis of AOAC International. $16^{\text {th }}$ ed. Washington, 1995. $1200 \mathrm{p}$.

2 BRASIL. Ministério da Saúde. Agência Nacional de Vigilância Sanitária. RDC No 263 de 22 de setembro de 2005. Aprova o regulamento técnico para produtos de cereais, amidos, farinhas e farelos. Diário Oficial [da] República Federativa do Brasil, Brasília, 2005.

3 CHAVES, J. B. P.; SPROSSER, R. L. Práticas de laboratório de análise sensorial de alimentos e bebidas. Viçosa: UFV, 2001. $81 \mathrm{p}$.

4 FASOLIN, L. H.; ALMEIDA, G. C.; CASTANHO, P. S.; NETTO-OLIVEIRA, E. R. Biscoitos produzidos com farinha de banana: avaliações química, física e sensorial. Ciência e Tec. de Alim., Campinas, v. 27, n. 3, p. 787-792, 2007.

5 KIRSCHNIK, P. G. Avaliação da estabilidade de produtos obtidos de carne mecanicamente separada de tilápia nilótica (Oreochromis niloticus). 2007. 102 f. Tese (Doutorado em Aqüicultura). Universidade Estadual Paulista, Jaboticabal, 2007.

6 MEILGAARD, M.; CIVILLE, G. V.; CARR, B. T. Sensory evaluation techniques. $2^{\text {nd }}$ ed. Flórida: CRC Press, 1991. 354 p.

7 MINIM, V. P. R. Análise sensorial: estudo com consumidores. Viçosa: Ed. UFV, 2006. 225 p.

8 PESSATTI, M. L. Aproveitamento dos subprodutos do pescado: meta 11. Itajaí: Universidade do Vale do Itajaí, 2001. (Relatório final de ações prioritárias ao desenvolvimento da pesca e aqüicultura no sul do Brasil, convênio Ministério da Agricultura, Pecuária e Abastecimento - MAPA)

9 SEIBEL, N. F.; SOUZA-SOARES, L. A. Produção de silagem química com resíduos de pescado marinho. Brazilian Journal of Food Technology, Campinas, v. 6, n. 2, p. 333-337, 2003. 
10 STEVANATO, F. B.; SOUZA, N. E.; MATSUSHITA, M.; VISENTAINER, J. V. Aproveitamento de resíduos, valor nutricional e avaliação da degradação de pescado. PUBVET, Londrina, v. 1, n. 7, 2007. Disponível em: http://www.pubvet.com.br/ artigos_imp.asp?artigo=171> Acesso em: 9 mar 2012.

11 STONE, H.; SIDEL, J. L. Sensory evaluation practices. $3^{\text {rd }}$ ed. Boston: Elsevier Academic Press, 2004. 377 p.

12 TSEN, C. C. Regular and protein fortified cookies from composite flours. Cereal Foods World, v. 21, n. 12, p. 634-637, 1976.

13 VIDAL, J. M. A. Utilização de resíduos de filetagem de tilápia-do-Nilo (Oreochromis niloticus) na obtenção de concentrado protéico de peixe: caracterização físico-química e aceitação sensorial. 2007. 108 f. Dissertação (Mestrado em Tecnologia de Alimentos), Universidade Federal do Ceará, Fortaleza, 2007. 